Aula Rumana N, dkk- Penerimaan Pasien Terhadap Sistem...

\title{
PENERIMAAN PASIEN TERHADAP SISTEM PENDAFTARAN ONLINE MENGGUNAKAN TECHNOLOGY ACCEPTANCE MODEL DI RSUP FATMAWATI
}

\author{
NANDA AULA RUMANA \\ ELINA INTAN APZARI \\ DEASY ROSMALA DEWI \\ LAELA INDAWATI \\ NOOR YULIA \\ Program Studi Rekam Medis dan Informasi Kesehatan \\ Universitas Esa Unggul \\ Jalan Arjuna Utara no. 9 Tol Tomang Kebon Jeruk Jakarta Barat \\ Email: nanda.rumana@esaunggul.ac.id
}

\begin{abstract}
Online registration system is a system where patients register to get an examination from a health service facility by utilizing technology. Online registration system aims to simplify the registration process, but its implementation still leaves many problems and to find out how accepted the online registration system is by the user or patient, then a model is needed. Technology Acceptance Model is a model to measure the factors that affect the receipt of an information system. This study aims to identify the description of patient acceptance of online registration and the obstacles that occur when using online registration. The research method used is quantitative analysis with cross-sectional research design. From the results of the study involving 106 respondents $48 \%$ of them said they had used an online registration system. Characteristics of patients in Fatmawati General Hospital are mostly female (69.81\%), average age 36 years, most recent education is high school education (59.4\%), married (84\%), most work is housewife $(31,1 \%)$, the most ethnic groups are Javanese (33\%). Average family income> UMR (69\%). Factors that influence patient acceptance of the online registration system at Fatmawati General Hospital are the Perceived Ease of Use factor and Behavioral Intention to Use.. The most influential factor on patient acceptance in the online registration system is Behavioral Intention to Use. It is recommended that RSUP Fatmawati to further socialize how to use online registration to patientsthe public. In addition it is hoped that the system will not only be made on Android, but also on $i O S$ so that its reach is wider, and it is expected that the availability of information related to patient limits in the clinic.
\end{abstract}

Key words: Online Registration, Characteristics, Technology Acceptance Model.

\begin{abstract}
Abstrak. Sistem pendaftaran online adalah sebuah sistem dimana pasien melakukan pendaftaran untuk mendapatkan pemeriksaan dari fasilitas pelayanan kesehatan dengan memanfaatkan teknologi. Sistem pendaftaran online bertujuan untuk mempermudah proses pendaftaran, akan tetapi pelaksanaannya masih menyisakan banyak masalah dan untuk mengetahui seberapa diterimanya sistem pendaftaran online oleh pengguna atau pasien maka diperlukan sebuah model. Technology Acceptance Model merupakan sebuah model untuk mengukur faktor yang mempengaruhi diterimanya suatu sistem informasi. Penelitian ini bertujuan untuk mengidentifikasi gambaran penerimaan pasien terhadap pendaftaran online serta kendala yang terjadi saat menggunakan pendaftaran online. Metode penelitian yang digunakan adalah analisis kuantitatif dengan desain
\end{abstract}


Aula Rumana N, dkk- Penerimaan Pasien Terhadap Sistem...

penelitian crossectional. Dari hasil penelitian yang melibatkan 106 responden 48\% diantaranya menyatakan sudah menggunakan sistem pendaftaran online. Karakteristik pasien di RSUP Fatmawati mayoritas berjenis kelamin perempuan $(69,81 \%)$, umur ratarata 36 tahun, pendidikan terakhir kebanyakan berpendidikan SMA $(59,4 \%)$, berstatus menikah (84\%), pekerjaan terbanyak yaitu Ibu rumah tangga $(31,1 \%)$, suku terbanyak yaitu jawa (33\%). Pendapatan rata-rata keluarga >UMR (69\%). factor yang mempengaruhi penerimaan pasien terhadap sistem pendaftaran online di RSUP Fatmawati adalah faktor Perceived Ease of Use (persepsi kemudahan penggunaan), Behavioral Intention to Use (niat perilaku). Faktor yang paling berpengaruh terhadap penerimaan pasien pada sistem pendaftaran online adalah faktor Behavioral Intention to Use/niat perilaku.. Disarankan RSUP Fatmawati untuk lebih menyosialisasikan cara menggunakan pendaftaran online kepada pasien/masyarakat. Selain itu diharapkan sistem tidak hanya dibuat di android, tapi juga di iOS agar jangkauannya lebih luas, dan diharapkan tersedianya informasi terkait batasan pasien di poliklinik.

Kata Kunci: Pendaftaran Online, Karakteristik, Technology Acceptance Model.

\section{PENDAHULUAN}

Rumah sakit adalah institusi pelayanan kesehatan yang menyelenggarakan pelayanan kesehatan perorangan secara paripurna yang menyediakan rawat inap, rawat jalan, dan gawat darurat. Untuk menjalankan proses pelayanan kesehatan setiap rumah sakit berkewajiban untuk menyelenggarakan rekam medis (Kemenkes, 2009). Rekam medis adalah berkas yang berisikan catatan dan dokumen tentang identitas pasien, pemeriksaan, pengobatan, tindakan dan pelayanan lain yang telah diberikan kepada pasien (Kemenkes, 2008).

Pelayanan pasien di rumah sakit dimulai dari tempat pendaftaran sampai pasien memperoleh rekam medis yang akan digunakan untuk mendapatkan pelayanan kesehatan. Loket penerimaan pasien rawat jalan adalah pelayanan pertama yang akan di terima oleh pasien dan secara langsung berinteraksi dengan pasien dan merupakan salah satu bagian di rumah sakit yang mengatur pendaftaran dan penerimaan pasien rawat jalan yang akan berobat di rumah sakit tersebut (Listyorini \& Kalbuadi, 2017).

Pada saat ini pemerintah membuat suatu sistem baru yaitu sistem pendaftaran online. Dengan adanya sistem tersebut, diharapkan dapat memudahkan pasien dalam melakukan pendaftaran untuk berobat. Sistem pendaftaran online dapat diperoleh melalui website rumah sakit dan bisa juga di download pada play store. Saat ini ada 33 rumah sakit yang sudah menyelenggarakan sistem pendaftaran online yaitu salah satunya Rumah Sakit Umum Pusat Fatmawati yang mulai di operasikan pada tanggal 19 november 2019.

Sistem pendaftaran online bertujuan untuk mempermudah proses pendaftaran, akan tetapi pelaksanaannya masih menyisakan banyak masalah dan untuk mengetahui seberapa diterimanya sistem pendaftaran online oleh pengguna atau pasien maka diperlukan sebuah metode. Metode yang dapat digunakan untuk mengukur penerimaan dan penggunaan teknologi yaitu metode Technology Acceptance Model (TAM) (Sapty, Djoko, \& David, 2017). TAM merupakan metode yang menjelaskan perilaku pengguna teknologi informasi yang berlandaskan pada kepercayaan (Beliefs), sikap (Attitude), minat (intention) dan hubungan perilaku pengguna (User Behavior Relationship) (Saputra \& Misfariyan, 2013).

Pengguna sistem pendaftaran online di Rumah Sakit Umum Pusat Fatmawati pada bulan Agustus 2018 yaitu berjumlah 5.476 pengguna dari 25.226 pasien (21.73\%). Pada bulan September 2018 yaitu berjumlah 5.626 pengguna dari 26.080 pasien (21.58\%). Pada bulan Oktober 2018 yaitu berjumlah 5.831 pengguna dari 26.690 pasien (21.85\%). Berdasarkan data tersebut maka disimpulkan bahwa pengguna sistem pendaftaran online 
Aula Rumana N, dkk- Penerimaan Pasien Terhadap Sistem...

di Rumah Sakit Umum Pusat Fatmawati termasuk dalam perubahan yang belum terlalu signifikan.

Berdasarkan penelitian sebelumnya yang menggunakan metode TAM pada bidang kesehatan yaitu Penerimaan Sistem Pendaftaran Online BPJS Kesehatan Cabang Jember (Prasastika, Winarno, \& Kartika, 2015), Analisis Penerimaan Sistem Informasi Manajemen Rumah Sakit Umum Daerah Bangkinang (Saputra \& Misfariyan, 2013), Evaluasi Sigizi di Dinas Kesehatan Kabupaten Trenggalek dengan Pemodelan Entended TAM (Winarno, Adhipta, \& Triana, 2014), Analisis Evaluasi Implementasi Sik 5Ng Pada Bidan Desa Dengan Metode Tam Di Wilayah Kerja Dinas Kesehatan Kabupaten Demak Tahun 2016 (Gaol, Mawarni, \& Joko, 2017), Evaluasi Pemanfaatan Sistem Informasi Manajemen Demam Berdarah Dengue (SIM DBD) dengan Technology Acceptance Model (Tam) di Rumah Sakit Wilayah Kerja Dinas Kesehatan Kota Semarang Tahun 2011 (Pratiwi, 2012), dari hasil penelitian tersebut menunjukan bahwa sistem pendaftaran online diterima oleh pengguna atau pasien yang mendaftar.

Tujuan dalam penelitian ini yaitu mengetahui gambaran karakteristik pasien yang melakukan pendaftaran online dan non online serta mengetahui gambaran penerimaan pasien terhadap sistem pendaftaran online menggunakan TAM di Rumah Sakit Umum Pusat Fatmawati tahun 2019.

\section{METODE}

Penelitian ini menggunakan desain penelitian cross sectional dengan pendekatan kuantitatif. Uji hipotesis yang menggunakan uji regresi linier berganda di mana variabel independennnya adalah Actual System Usage (penggunaan aktual) sedangkan variabel independennya adalah Perceived Ease of Use (persepsi kemudahan penggunaan), Perceived Usefulness (kegunaan yang dirasakan), Attitude Towards Using (sikap terhadap penggunaan), Behavioral Intention to Use (niat perilaku).

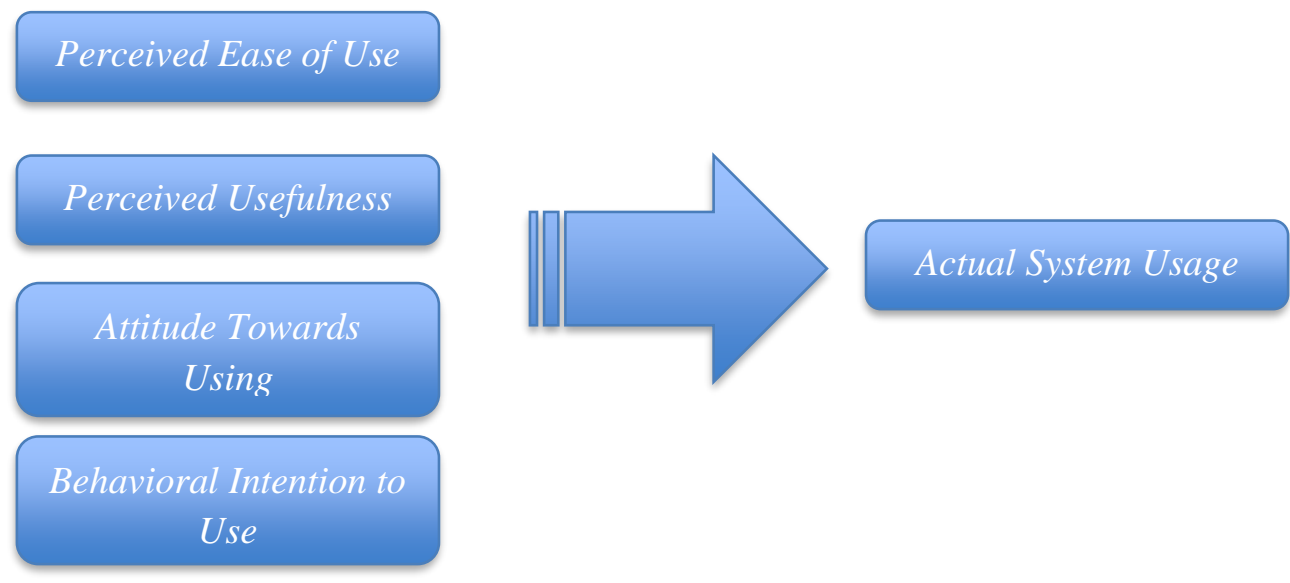

Gambar 1. Kerangka Konsep Penelitian

Untuk menilai seberapa diterimanya sebuah aplikasi pendaftara online, digunakan metode Technology Acceptance Model (TAM). TAM merupakan metode yang menjelaskan perilaku pengguna teknologi informasi yang berlandaskan pada kepercayaan (Beliefs), sikap (Attitude), minat (intention) dan hubungan perilaku pengguna (User Behavior Relationship) (Saputra, 2014). TAM pertama kali dikembangkan oleh Davis (1989) berdasarkan model Theory of Reasoned Action (TRA). TAM merupakan model parsimoni, yaitu model yang sederhana tetapi valid. TAM juga telah diuji dengan banyak 
Aula Rumana N, dkk- Penerimaan Pasien Terhadap Sistem...

penelitian yang hasilnya TAM merupakan model yang baik khususnya jika dibandingkan dengan model TRA (Theory of Reason Action) dan TPB (Theory of Planned Behavior) (Ratri, 2016).

Populasi yang digunakan dalam penelitian ini adalah seluruh pasien yang melakukan pendaftaran di Rumah Sakit Umum Pusat Fatmawati pada bulan Februari-April tahun 2019. Sampel dalam penelitian ini yaitu pasien pendaftaran online dan non online di Rumah Sakit Umum Pusat Fatmawati yang terpilih menjadi responden. Jumlah responden yang diperlukan dalam penelitian ini sebanyak 106 responden. Analisis data menggunakan software SPSS (Statistical Package for The Social Sciences) versi 25.

\section{HASIL DAN PEMBAHASAN}

Tabel 1. Distribusi tipe pendaftaran pasien di RSUP Fatmawati Jakarta

\begin{tabular}{ccc}
\hline $\begin{array}{c}\text { Tipe } \\
\text { Pendaftaran }\end{array}$ & $\mathrm{N}$ & $\%$ \\
\hline Online & 51 & $49 \%$ \\
Non Online & 55 & $51 \%$ \\
\hline Total & 106 & $100 \%$ \\
\hline
\end{tabular}

Berdasarkan hasil penelitian terlihat bahwa, responden yang sudah menggunakan sistem pendaftaran online sebanyak $49 \%$ sisanya sebanyak $51 \%$ masih menggunakan sistem pendafaftaran non online.

Tabel 2. Gambaran Karakteristik pasien di RSUP Fatmawati Jakarta

\begin{tabular}{ccc}
\hline Karakteristik & N & \% \\
\hline Jenis Kelamin & & \\
\hline Perempuan & 74 & $69,81 \%$ \\
Laki-laki & 32 & $30,19 \%$ \\
\hline Usia & & \\
\hline Remaja Akhir (17-25 th) & 13 & $12.26 \%$ \\
Dewasa Awal (26-35 th) & 33 & $31.13 \%$ \\
Dewasa Akhir (36-45 th) & 42 & $39.62 \%$ \\
Lansia Awal (46-55 th) & 17 & $16.03 \%$ \\
Lansia Akhir (56-65 th) & 1 & $0.94 \%$ \\
\hline Pendidikan Terakhir & \\
\hline SD & 1 & $0,9 \%$ \\
SMP & 9 & $8,5 \%$ \\
SMA & 63 & $59,4 \%$ \\
D3 & 11 & $10,4 \%$ \\
S1 & 20 & $18,9 \%$ \\
S2 & 2 & $1,9 \%$ \\
\hline Status Pernikahan & & \\
\hline Menikah & 89 & $84 \%$ \\
Belum Menikah & 15 & $14 \%$
\end{tabular}


Aula Rumana N, dkk- Penerimaan Pasien Terhadap Sistem...

\begin{tabular}{ccc} 
Janda/Duda & 2 & $2 \%$ \\
\hline Pekerjaan & & \\
\hline PNS/TNI/POLRI & 5 & $4,7 \%$ \\
Wiraswasta & 22 & $20,8 \%$ \\
Pegawai swasta & 31 & $29,2 \%$ \\
Ibu Rumah Tangga & 33 & $31,1 \%$ \\
Pelajar & 6 & $5,7 \%$ \\
Guru/Dosen & 4 & $3,8 \%$ \\
Tidak bekerja & 3 & $2,8 \%$ \\
Lainnya & 2 & $1,9 \%$ \\
\hline \multicolumn{1}{c}{ Suku } & & \\
\hline Jawa & 35 & $33.01 \%$ \\
Batak & 8 & $7.54 \%$ \\
Betawi & 31 & $29.24 \%$ \\
Sunda & 26 & $24.52 \%$ \\
Lainnya & 6 & $5.66 \%$ \\
\hline Pendapatan Keluarga & \\
\hline (UMR DKI) Rp 3.648.035 & 73 & $68.86 \%$ \\
$\leq$ (UMR DKI) Rp 3.648.035 & 33 & $31.13 \%$ \\
\hline Total & $\mathbf{1 0 6}$ & $\mathbf{1 0 0 \%}$ \\
\hline
\end{tabular}

Tabel 2 menghasilkan hasil penelitian bahwa mayoritas responden berjenis kelamin perempuan $69,81 \%$, usia didominasi usia dewasa akhir ((36-45 tahun) sebanyak $39,62 \%$, pendidikan terakhir kebanyakan berpendidikan SMA 59,4\%, berstatus menikah $84 \%$, pekerjaan terbanyak yaitu Ibu rumah tangga $31,1 \%$, suku terbanyak yaitu jawa $33,01 \%$. Pendapatan rata-rata keluarga > UMR 68,86\%.

\section{Uji Asumsi Klasik}

Asumsi Eksistensi

Untuk tiap nilai dari variabel X (variabel independen), variabel $\mathrm{Y}$ (dependen) adalah variabel random yang mempunyai mean dan varian tertentu. Asumsi ini berkaitan dengan teknik pengambilan sampel. Untuk memenuhi asumsi ini, sampel yang diambil harus dilakukan secara random. Cara mengetahui asunsi eksistensi dengan cara melakukan analisis deskriptif variabel residual dari model, bila residual menunjukkan adanya mean mendekati nilai nol dan ada sebaran (varian atau standar deviasi) maka asumsi eksistensi terpenuhi.

Tabel 3. Asumsi Eksistensi

\begin{tabular}{cccccc}
\hline \multicolumn{5}{c}{ Residuals Statistics $^{\mathrm{a}}$} \\
\hline & Minimum & Maximum & Mean & $\begin{array}{c}\text { Std. } \\
\text { Deviation }\end{array}$ & $\mathrm{N}$ \\
\hline Residual & -3.558 & 2.830 & $\mathbf{0 . 0 0 0}$ & 1.276 & 51 \\
\hline
\end{tabular}

Berdasarkan tabel 3 terlihat bahwa nilai residual menunjukkan adanya mean 0,000 dan ada sebaran (varian atau standar deviasi) maka asumsi eksistensi terpenuhi. 
Aula Rumana N, dkk- Penerimaan Pasien Terhadap Sistem...

\section{Asumsi Independensi/Autokorelasi}

Suatu keadaan dimana masing-masing nilai Y bebas satu sama lain. Jadi nilai dari tiaptiap individu saling berdiri sendiri. Tidak diperbolehkan nilai observasi yang berbeda yang diukur dari satu individu diukur dua kali. Untuk mengetahui asumsi ini dilakukan dengan cara mengeluarkan uji Durbin Watson, bila nilai Durbin -2 s.d. +2 berarti asumsi independensi terpenuhi, sebaliknya bila nilai Durbin $\langle-2$ atau $>+2$ berarti asumsi tidak terpenuhi.

Tabel 4. Asumsi Independei/Autokorelasi

\begin{tabular}{cccccc}
\hline Model & $\mathrm{R}$ & $\mathrm{R}$ & $\begin{array}{c}\text { Adjusted } \\
\mathrm{R} \\
\text { Square } \\
\text { Square }\end{array}$ & $\begin{array}{c}\text { Std. } \\
\text { Error of } \\
\text { the } \\
\text { Estimate }\end{array}$ & $\begin{array}{c}\text { Durbin- } \\
\text { Watson }\end{array}$ \\
\hline 1 & $.882^{\mathrm{a}}$ & .778 & .759 & 1.330 & 2.060 \\
\hline
\end{tabular}

Nilai Durbin Watson pada tabel 4 menunjukkan angka mendekat +2 sehingga asumsi independensi sudah terpenuhi

\section{Asumsi Linieritas}

Nilai mean dari variabel Y untuk suatu kombinasi X1, X2, X3, .., Xk terletak pada garis/bidang linier yang dibentuk dari persamaan regresi. Untuk mengetahui asumsi linieritas dapat diketahui dari uji ANOVA (overall $F$ test) bila hasilnya signifilan ( $p$ value<alpha) maka model berbentuk linier.

Tabel 5. Asumsi Linieritas

\begin{tabular}{lllllll}
\hline \multirow{2}{*}{ Model } & $\begin{array}{c}\text { Sum of } \\
\text { Squares }\end{array}$ & df & $\begin{array}{c}\text { Mean } \\
\text { Square }\end{array}$ & F & Sig. \\
\hline 1 & Regression & 285.213 & 4 & 71.303 & 40.287 & 0.001 \\
\hline
\end{tabular}

Berdasarkan tabel 5 menunjukkan bahwa nilai $\mathrm{p}$ value sebesar 0,000 ( $\mathrm{p}$ value $<$ alpha) oleh karena itu asumsi linieritas terpenuhi.

\section{Asumsi Homoscedasticity}

Varian nilai variabel Y sama untuk semua nilai variabel X. Homoscedasticity dapat diketahui dengan melakukan pembuatan plot residual. Bila titik tebaran tidak berpola tertentu dan menyebar merata disekitar garis titik nol maka dapat disebut varian homogen pada setiap nilai $X$ dengan demikian asumsi homoscedasticity terpenuhi. Sebaliknya bila titik tebaran membentuk pola tertentu misalnya mengelompok di bawah atau di atas garis tengah nol, maka diduga variannya terjadi heteroscedasticity. 
Aula Rumana N, dkk- Penerimaan Pasien Terhadap Sistem...

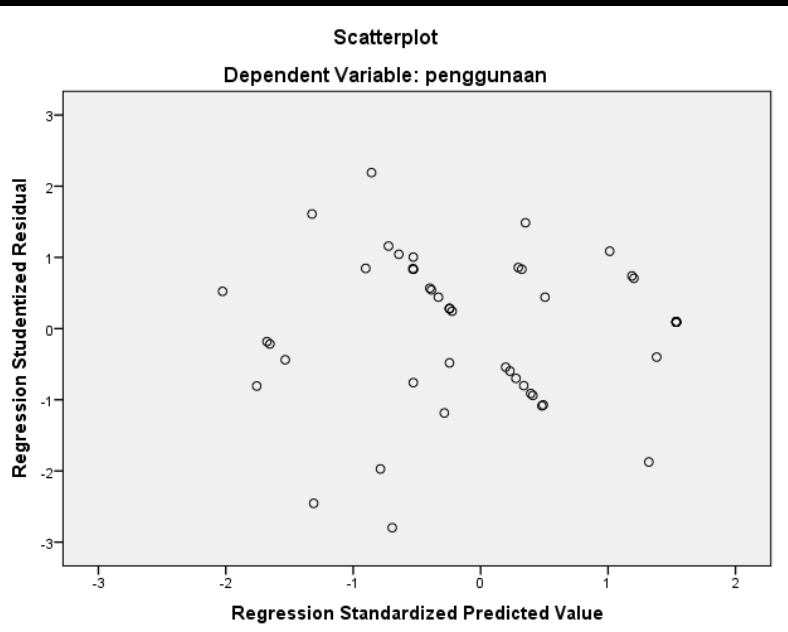

Gambar 2. Asumsi Homoscedasticity

Asumsi Homoscedasticity yang tersaji pada gambar 2 menunjukkan bahwa titik tebaran menyebar diseluruh garis dan tidak mengelompok di satu tempat sehingga asumsi homoscedasticity terpenuhi.

\section{Asumsi Normalitas}

Variabel Y mempunyai distribusi normal untuk setiap pengamatan variabel X. dapat diketahui dari Normal P-P Plot residual, bila data menyebar di sekitar garis diagonal dan mengikuti arah garis diagonal, maka model regresi memenuhi asumsi normalitas.

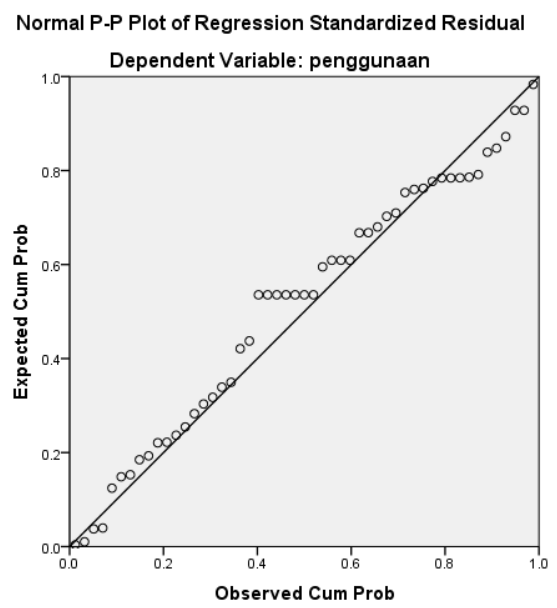

Gambar 3. Asumsi Normalitas

Gambar 3 merupakan hasil asumsi normalitas, berdasarkan hasil analisis terlihat bahwa titik tebaran menyebar di sekitar garis diagonal dan mengikuti arah garis diagonal, maka model regresi memenuhi asumsi normalitas.

\section{Asumsi Multicollinearity}

Dalam regresi linier tidak boleh terjadi sesama variabel independen berkorelasi secara kuat (multicollinearity). Untuk mendeteksi collinearity dapat diketahui dari nilai VIF (variance inflation factor), bila nilai VIF lebih dari 10 maka mengindikasikan telah terjadi collinearity. 
Aula Rumana N, dkk- Penerimaan Pasien Terhadap Sistem...

Tabel 6. Asumsi Multicollinearity

\begin{tabular}{ccc}
\hline & \multicolumn{2}{c}{ Collinearity Statistics } \\
\cline { 2 - 3 } Variabel & Tolerance & VIF \\
\hline Perceived Ease of Use & .506 & 1.976 \\
Perceived Usefulness & .304 & 3.289 \\
Attitude Towards Using & .620 & 1.613 \\
Behavioral Intention to Use & .521 & 1.919 \\
\hline
\end{tabular}

Tabel 6 menunjukkan hasil bahwa nilai VIF tidak ada yang melebihi 10 sehingga hal tersebut mengindikasikan tidak terjadi collinearity antar variabel independen.

Berdasarkan ke enam asumsi diatas, maka model akhir yang akan terbentuk sudah memenuhi seluruh asumsi sehingga hasil dapat digunakan untuk menentukan kesimpulan dalam penelitian.

\section{Uji Model}

\begin{tabular}{ccccc}
\multicolumn{6}{c}{ Tabel 7. Uji Model } \\
\hline Uji Model & R & R Square & Sig. & Keterangan \\
\hline $\begin{array}{c}\text { Penerimaan Pasien terhadap } \\
\text { Sistem Pendaftaran Online di } \\
\text { RSUP Fatmawati }\end{array}$ & 0.875 & 0.766 & 0.001 & $\mathrm{H}_{0}$ ditolak \\
\hline
\end{tabular}

Tabel 7 menghasilkan data uji model secara keseluruhan menunjukkan bahwa model signifikan/saling mempengaruhi dilihat dari nilai signifikansi $<0,05(5 \%)$. Artinya bahwa secara simultan persepsi kemudahan penggunaan dan niat perilaku secara signifikan mempengaruhi penerimaan pasien terhadap sistem pendaftaran online. Nilai Rsquare didapatkan 0,766 artinya artinya bahwa model regresi yang diperoleh dapat menjelaskan $76,6 \%$ variasi variabel dependen atau dengan kata lain variabel persepsi kemudahan dan niat perilaku dapat menjelaskan variasi penerimaan pasien sebesar $76,6 \%$.

\section{Model Akhir}

Tabel 8. Model Akhir Faktor yang Mempengaruhi Penerimaan Pasien terhadap Sistem Pendaftaran Online di RSUP Fatmawati

\begin{tabular}{ccccc}
\hline Variabel & B & $\begin{array}{c}\text { Std. } \\
\text { Error }\end{array}$ & Beta & Sig. \\
\hline (Constant) & -1.598 & 1.606 & & 0.325 \\
Perceived Ease of Use & 0.236 & 0.063 & 0.286 & 0.000 \\
Behavioral Intention to Use & 0.575 & 0.061 & 0.721 & 0.000 \\
\hline
\end{tabular}

Berdasarkan analisis multivariat regresi linier berganda menggunakan model factor prediksi, maka factor yang mempengaruhi penerimaan pasien terhadap sistem pendaftaran 
Aula Rumana N, dkk- Penerimaan Pasien Terhadap Sistem...

online di RSUP Fatmawati adalah faktor Perceived Ease of Use (persepsi kemudahan penggunaan), Behavioral Intention to Use (niat perilaku). Faktor yang paling berpengaruh terhadap penerimaan pasien pada sistem pendaftaran online adalah faktor Behavioral Intention to Use/niat perilaku (Beta 0,721).

Persamaan garis yang terbentuk adalah

Penerimaan pasien terhadap sistem pendaftaran online $=-1,598+0,236$ Perceived Ease of Use $+0,575$ Behavioral Intention to Use

Sistem pendaftaran online merupakan salah satu wujud dari pemerintah yang mewajibkan setiap rumah sakit untuk melaksanakan Sistem Informasi Rumah Sakit (Kemenkes RI, 2011). Responden merasa mempermudah pelayanan dan efisiensi waktu, mudah digunakan dan dipahami(Prasastika et al., 2015). Dalam penelitian terlihat bahwa penerimaan pasien terhadap sistem pendaftaran online di RSUP fatmawati dipengaruhi oleh 2 faktor yaitu kemudahan dalam penggunaan dan niat perilaku untuk menggunakan. Sejalan dengan penelitian Mambu et al dimana mahasiswa mau menggunakan aplikasi sistem informasi Unklab (SIU) dari aplikasi tersebut mudah digunakan (Mambu, Jonathan, Rumawouw, \& Liem, 2019). Sebuah aplikasi akan lebih banyak diterima oleh pengguna jika sistem yang terbentuk mudah digunakan/user friendly. Selain kemudahan, niat perilaku untuk menggunakan juga berpengaruh terhadap penerimaan pasien hal ini sejalan dengan penelitian wang dimana niat menggunakan sebuah sistem berhubungan positif dengan penerimaan sistem (Wang, 2008). Sikap seseorang dalam memutuskan menggunakan sesuatu biasanya sejalan dengan pengetahuan. Apabila pasien memiliki pengetahuan yang cukup tentang sistem pendaftaran online, maka akan dengan mudah pasien menerima sebuah hal baru. Rendahnya pengetahuan masih didapati pada masyarakat Indonesia (Apriani \& Rumana, 2018) sehingga mempengaruhi keputusan penerimaan terhadap sesuatu.

\section{PENUTUP \\ Simpulan}

Berdasarkan hasil penelitian terlihat bahwa, responden yang sudah menggunakan sistem pendaftaran online sebanyak $49 \%$ sisanya sebanyak $51 \%$ masih menggunakan sistem pendafaftaran non online. Mayoritas responden berjenis kelamin perempuan $69,81 \%$, usia didominasi usia dewasa akhir ((36-45 tahun) sebanyak 39,62\%, pendidikan terakhir kebanyakan berpendidikan SMA 59,4\%, berstatus menikah $84 \%$, pekerjaan terbanyak yaitu Ibu rumah tangga $31,1 \%$, suku terbanyak yaitu jawa $33,01 \%$. Pendapatan rata-rata keluarga > UMR 68,86\%.

Faktor yang mempengaruhi penerimaan pasien terhadap sistem pendaftaran online di RSUP Fatmawati adalah faktor Perceived Ease of Use (persepsi kemudahan penggunaan), Behavioral Intention to Use (niat perilaku). Faktor yang paling berpengaruh terhadap penerimaan pasien pada sistem pendaftaran online adalah faktor Behavioral Intention to Use/niat perilaku

\section{Saran}

Disarankan RSUP Fatmawati untuk lebih menyosialisasikan cara menggunakan pendaftaran online kepada pasien/masyarakat. Selain itu diharapkan sistem tidak hanya dibuat di android, tapi juga di iOS agar jangkauannya lebih luas, dan diharapkan tersedianya informasi terkait batasan pasien di poliklinik.

\section{DAFTAR PUSTAKA}

Apriani, L., \& Rumana, N. A. (2018). Karakteristik dan Pengetahuan Pasien tentang BPJS 
Aula Rumana N, dkk- Penerimaan Pasien Terhadap Sistem...

Kesehatan di Puskesmas Kecamatan Kebon Jeruk Characteristics and Knowledge of Patients about BPJS Health in Kebon Jeruk District Health Center. Jurnal Penelitian Dan Pengembangan Pelayanan Kesehatan, 2(3), 191-197. https://doi.org/https://doi.org/10.22435/jpppk.v2i3.851

Gaol, A. L. L., Mawarni, A., \& Joko, N. (2017). Analisis Evaluasi Implementasi Sik 5Ng Pada Bidan Desa Dengan Metode Tam Di Wilayah Kerja Dinas Kesehatan Kabupaten Demak Tahun 2016. Jurnal Kesehatan Masyarakat (e-Journal), 5(4), 180-189.

Kemenkes. (2008). Peraturan Menteri Kesehatan No.269/MENKES/PER/III/2008 tentang Rekam Medis. Jakarta: Menteri Kesehatan.

Kemenkes. (2009). Undang-undang No. 44 tentang Rumah Sakit. Peraturan Presiden. Jakarta: Presiden RI. https://doi.org/10.1017/CBO9781107415324.004

Kemenkes RI. (2011). Peraturan Menteri Kesehatan Republik Indonesia No.1171/Menkes/PER/VI/2011 Sistem Informasi Rumah Sakit. https://doi.org/10.1016/j.proeng.2015.12.490

Listyorini, P. I., \& Kalbuadi, R. P. (2017). Faktor-Faktor Yang Mempengaruhi Kecepatan Pelayanan. Jurnal Ilmiah Rekam Medis Dan Informatika Kesehatan, 7(2), 36-43.

Mambu, J. Y., Jonathan, G., Rumawouw, G. M., \& Liem, A. T. (2019). Analisis Kemanfaatan dan Kemudahan Sistem Informasi Unklab (SIU) menggunakan Technology Acceptance Model (TAM). Creative Information Technology Journal, 5(2), 95. https://doi.org/10.24076/citec.2018v5i2.175

Prasastika, K., Winarno, W. A., \& Kartika. (2015). Pengujian Teori Technology Acceptance Model ( TAM) Untuk Memprediksi Penerimaan Sistem Pendaftaran Online BPJS Kesehatan Cabang Jember ( Theory Test Technology Acceptance Model ( TAM ) Revenue System For Predicting The Health Branch Registration Online B. Universitas Jember.

Pratiwi, A. (2012). Evaluasi Pemanfaatan Sistem Informasi Manajemen Demam Berdarah Dengue (SIM DBD) dengan Technology Acceptance Model (Tam) di Rumah Sakit Wilayah Kerja Dinas Kesehatan Kota Semarang Tahun 2011. Universitas Diponegoro. https://doi.org/10.1017/CBO9781107415324.004

Ratri, S. M. (2016). Analisis Faktor-Faktor Yang Memengaruhi Penggunaan E-Learning Moodle Oleh Guru Smk Negeri 2 Yogyakarta Dengan Pendekatan Technology Acceptance Model (Tam). Universitas Negeri Yogyakarta.

Sapty, R. F., Djoko, B., \& David, P. (2017). Analisis Penerimaan e-Learning Menggunakan Technology Acceptance Model ( TAM ) ( Studi Kasus: Universitas Atma Jaya Yogyakarta ), 1(2), 85-95. https://doi.org/10.21460/jutei.2017.12.20

Saputra, E. (2014). Analisis Penerimaan Sistem Informasi Manajemen Rumah Sakit Umum Daerah Bangkinang Menggunakan Metode Technology Acceptance Model ( TAM ). Jurnal Sistem Informasi.

Saputra, E., \& Misfariyan. (2013). Analisis Penerimaan Sistem Informasi Manajemen Rumah Sakit Umum Daerah Bangkinang Menggunakan Metode Technology Acceptance Model (TAM). SiTekin Jurnal Sains, Teknologi Dan Industri, 10(2).

Wang, Y. S. (2008). Assessing e-commerce systems success: A respecification and validation of the DeLone and McLean model of IS success. Information Systems Journal, 18(5), 529-557. https://doi.org/10.1111/j.1365-2575.2007.00268.x

Winarno, W. W., Adhipta, D., \& Triana, N. H. (2014). Evaluasi Sigizi di Dinas Kesehatan Kabupaten Trenggalek dengan Pemodelan Entented TAM. In Seminar Nasional Teknologi Informasi dan Multimedia (pp. 47-52). Yogyakarta: STMIK AMIKOM Yogyakarta. 